\title{
Cytokeratin 17 mRNA expression has potential for diagnostic marker of oral squamous cell carcinoma
}

Takeshi Toyoshima $\cdot$ Eleftherios Vairaktaris •

Emeka Nkenke • Karl Andreas Schlegel •

Friedrich Wilhelm Neukam · Jutta Ries

Published online: 17 January 2008

(C) Springer-Verlag 2007

Erratum to: J Cancer Res Clin Oncol

DOI 10.1007/s00432-007-0308-8

Owing to a technical problem, data in Table 2 was incorrect. The revised version of Table 2 is given here.

The online version of the original article can be found under doi: 10.1007/s00432-007-0308-8.

T. Toyoshima $\cdot$ E. Nkenke $\cdot$ K. A. Schlegel · F. W. Neukam ·

J. Ries ( $\square)$

Department of Oral and Maxillofacial Surgery,

University of Erlangen-Nuremberg,

Glueckstrasse 11, 91054 Erlangen, Germany

e-mail: Jutta.Ries@uk-erlangen.de

E. Vairaktaris

Department of Oral and Maxillofacial Surgery,

University of Athens, Vas. SoWas 93 and Dim. Soutsou 1,

Athens 11521, Greece 
Table 2 Association between CK expressions and clinicopathological parameters in all patients with OSCC

\begin{tabular}{|c|c|c|c|c|c|c|c|}
\hline \multirow[t]{2}{*}{ Variables } & \multirow{2}{*}{$\begin{array}{l}\text { Number } \\
\text { of cases }\end{array}$} & \multicolumn{3}{|c|}{ Number of positive cases ${ }^{\mathrm{a}}$} & \multicolumn{3}{|c|}{ Mean value of CK mRNA RQ } \\
\hline & & CK 17 & CK 19 & CK 20 & CK 17 & CK 19 & CK 20 \\
\hline Total number & 56 & $53(94.6 \%)$ & $18(32.1 \%)$ & $7(12.5 \%)$ & $12.38 \pm 5.67$ & $4.40 \pm 5.23$ & $2.74 \pm 2.63$ \\
\hline \multicolumn{8}{|l|}{ Tumor size } \\
\hline 1 & 9 & 8 & 0 & 0 & $11.54 \pm 5.43$ & $0.47 \pm 0.95$ & $1.24 \pm 1.76$ \\
\hline 2 & 15 & 15 & 4 & 3 & $15.55 \pm 6.23$ & $2.54 \pm 2.14$ & $4.02 \pm 3.68$ \\
\hline 3 & 5 & 5 & 3 & 1 & $13.02 \pm 5.00$ & $11.44 \pm 7.81$ & ND \\
\hline 4 & 27 & 25 & 11 & 3 & $10.77 \pm 5.03$ & $4.86 \pm 5.29$ & $2.50 \pm 2.39$ \\
\hline $1+2$ & 24 & 23 & 4 & 4 & $14.05 \pm 6.15$ & $1.85 \pm 2.05$ & $3.23 \pm 3.38$ \\
\hline $3+4$ & 32 & 30 & $14(P<0.05)^{\mathrm{b}}$ & & $11.12 \pm 5.01$ & $5.68 \pm 5.88$ & $2.52 \pm 2.30$ \\
\hline \multicolumn{8}{|c|}{ State of lymph node } \\
\hline Positive $(1+2)$ & 31 & $31(P<0.05)$ & 13 & $7(P<0.03)$ & $13.18 \pm 5.69$ & $3.28 \pm 4.69$ & $1.83 \pm 2.52$ \\
\hline Negative (0) & 25 & 22 & 5 & 0 & $11.38 \pm 5.60$ & $2.44 \pm 4.64$ & $0.63 \pm 0.73$ \\
\hline \multicolumn{8}{|l|}{ Clinical stage ${ }^{c}$} \\
\hline Early $(\mathrm{I}+\mathrm{II})$ & 16 & 15 & 2 & 1 & $12.11 \pm 5.52$ & $1.80 \pm 1.96$ & $3.87 \pm 4.73$ \\
\hline Late (III + IV) & 40 & 38 & $16(P<0.05)$ & 6 & $12.49 \pm 5.79$ & $5.03 \pm 5.60$ & $2.56 \pm 2.31$ \\
\hline \multicolumn{8}{|c|}{ Differentiation grade ${ }^{\mathrm{d}}$} \\
\hline Well (G1) & 5 & 5 & 0 & 0 & $13.72 \pm 5.94$ & ND & ND \\
\hline Moderate (G2) & 35 & 34 & 9 & 5 & $12.65 \pm 5.35$ & $3.59 \pm 3.60$ & $2.49 \pm 2.28$ \\
\hline Poor (G3) & 16 & 14 & $9(P<0.03)$ & 2 & $11.70 \pm 6.54$ & $6.03 \pm 7.47$ & $3.41 \pm 3.56$ \\
\hline
\end{tabular}

$N D$ not detected

a Value of CK mRNA RQ was defined as positive if the value was higher more than 2.5 and as negative if less than 2.5, as described in the Materials and methods section

b The statistical significance of the association was determined by the chi-square test

$c$ The clinical stages were determined according to the International Union Against Cancer (UICC)

d The histological differentiation grades were determined according to the WHO 